\title{
SYMPATHETIC OVERACTIVITY AND ARRHYTHMIAS IN TETANUS: ELECTROCARDIOGRAPHIC ANALYSIS
}

\section{SUMMARY}

As a result of the advances in the control of pulmonary insufficiency in tetanus, the cardiovascular system has increasingly been shown to be a determining factor in morbidity and mortality but detailed knowledge of the cardiovascular complications in tetanus is scanty. The $24 \mathrm{~h}-$ Holter was carried out in order to detect arrhythmias and sympathetic overactivity in 38 tetanus patients admitted to an ICU. The SDNN Index (standard deviation from the normal R-to-R intervals), was useful in detecting adrenergic tonus, and ranged from $64.1 \pm 27$ in the more severe forms of tetanus to $125 \pm 69$ in the milder ones. Sympathetic overactivity occurred in $86.2 \%$ of the more severe forms of the disease, but was also detected in $33 \%$ of the milder forms. Half the patients had their sympathetic overactivity detected only by the Holter. The most frequent arrhythmias were isolated supraventricular (55.2\%) and ventricular (39.4\%) extrasystoles. There was no association of the arrhythmias with the clinical form of tetanus or with the presence of sympathetic overactivity. The present study demonstrated that major cardiovascular dysfunction, particularly sympathetic overactivity, occurs in all forms of tetanus, even in the milder ones. This has not been effectively detected with traditional monitoring in ICU and may not be properly treated.

KEYWORDS: Tetanus; Cardiovascular system; Arrhythmias; Sympathetic overactivity.

\section{INTRODUCTION}

It is estimated that $1,000,000$ cases of tetanus per year occur throughout the world ${ }^{4}$. A higher incidence occurs in countries with poor social, economic and educational indicators ${ }^{14,30}$.

Mortality was around $85 \%$ before the introduction of treatment with antitetanus immunoglobulin; with immunoglobulin, mortality remains between 10 and $60 \%$ 3,9,13,14,18,30. This variation depends mainly on the facilities of the health unit where the treatment is conducted $^{19,21,25,30}$, on the patient's age ${ }^{2,14,17}$ and on the severity of the disease $^{14,30}$.

Recently, with the advent of more effective control and prophylaxis of respiratory complications in intensive care units (ICU), formerly the main cause of death $(61 \text { to } 80 \%)^{1,3,4}$, the effects of tetanus on the cardiovascular system have been observed and seem to cause increasing morbidity and mortality in these patients ${ }^{5,7,8,18,21,26}$.

The cardiovascular manifestations of tetanus consist of disturbances of heart rate and rhythm, blood pressure instability, arrhythmias, myocardial dysfunction and sympathetic overactivity ${ }^{10,15,20,30}$. They may be due to the direct action of the tetanus toxin on the heart, to the drugs used to control rigidity and spasms, and to the hypersympathetic state induced by the failure to inhibit adrenal release of catecholamines s $^{7,8,23,29}$.

One study shows that this dysautonomia is responsible for nearly $30 \%$ of deaths and that only $26 \%$ of the tetanus patients who survived the disease showed a clinical manifestation of sympathetic overactivity ${ }^{28}$.

Current literature on the topic is scanty and states that patients who develop more severe clinical conditions more frequently present hemodynamic, myocardial or electrocardiographic abnormalities than those with the milder forms of tetanus $3,4,10,28,30$.

The literature reinforces the idea that the sympathetic overactive syndrome occurs only in very severe tetanus $1,7,14,30$, and fails to take into account the possibility of hypercatecholaminemia without any obvious clinical manifestation in patients with the less severe forms of the disease.

These complications remain a challenge and have motivated the authors to study the association between the presence of arrhythmias and sympathetic nervous system hyperactivity and the severity of the 
clinical form of tetanus, for a better knowledge of this relationship could contribute to more prompt and effective treatment of these patients.

\section{MATERIALS AND METHODS}

The study population included all patients aged 12 years or over admitted to the Intensive Care Unit of the Division of Infectious and Parasitic Diseases (ICU-IPDS) of the Oswaldo Cruz University Hospital of Pernambuco State University (OCUH-PSU) in a consecutive order between October 1998 and November 2000 with a clinical diagnosis of tetanus, and no cardiocirculatory disease at admission. The patients or a legal guardian signed a written authorization before enrolment in the study. The study was approved by the Ethics Committee of the Hospital.

A diagnosis of tetanus was based on epidemiological data, clinical history and physical signs. The patients with a recent wound history and muscular rigidity in one or more groups of muscles, with or without muscular spasms (spontaneous or triggered by stimuli) ${ }^{4,30}$, were included as cases of tetanus. Tetanus was classified, according to MIRANDA-FILHO et al. $(2004)^{13}$, into:

mild tetanus: trismus, dysphagia and generalized rigidity; moderate tetanus: patients with symptoms of the mild form of the disease, with mild and occasional spasms, usually resulting from stimuli;

severe tetanus: patients with symptoms of the moderate form of the disease, with recurrent spasms, usually triggered by minor or imperceptible stimuli;

very severe tetanus: patients with symptoms of the severe form of the disease, with severe and repetitive spasms difficult to control with medicaments, with or without signs of dysautonomia (mainly sympathetic overactivity). The presence of this clinically manifested overactivity characterizes the patient's tetanus as very severe, irrespective of the other clinical findings ${ }^{13}$.

At admission and at 2-day intervals the severity of the tetanus was classified according to clinical parameters and clinical manifestations of sympathetic overactivity that included increased sweat; blood pressure variations; heart rate or rhythm instability; sustained tachycardia away from the spasm; adynamic ileus; hyperglycemia; hyper- or hypothermia, all without other defined causes ${ }^{1,3,29,30}$; and ventricular and supraventricular arrhythmias. All patients were admitted to the ICU, used a cardiac monitor and had their blood pressure and heart rate recorded every two hours.

All the patients were also submitted to 24-hour electrocardiographic monitoring (Holter). The examination was carried out in the first ten days of hospitalization. The electrocardiographic data was recorded on magnetic cassette tapes, using a two-channel Dynamis 3002 recorder. The evaluation of the electrocardiograph monitoring for the 24-hour recording period was done with the DMS system, which consists of a tape analyzer and a specific program to analyze heart rate variability (DMS-1995) through the fluctuations of the R-to-R intervals in normal QRS complexes, in five minutes cycles, estimating the mean and standard deviation of its variability. This analysis was done in every cycle for the whole registering period, estimating the mean of the standard deviation for 24 hours. The sdnn index (mean of standard deviation of HRV of the normal R-to-R intervals) was the parameter used. The existence of sympathetic overactivity was identified either by clinical signs or by the SDNN Index ${ }^{11,12,22,24}$. When SDNN was lower than 100 milliseconds, the presence of dysautonomia was considered ${ }^{24}$.

For the analysis of the electrocardiographic monitoring (Holter) the patients were considered at the most severe stage of their progression. If the patient developed a more severe form of the disease after the Holter was done, a further examination was performed and the previous one was excluded from the analysis. This happened on two occasions. All the exams were performed by the same professional, at the electrocardiography service of the Chagas Disease Out-Clinic of the OCUH-PSU.

For the data analysis, the clinical conditions of the disease were regrouped into two categories, according to the clinical severity of the disease: Group A: mild and moderate forms; Group B: severe and very severe forms.

The association between groups A and B and the presence of electrocardiographic alterations was evaluated, as well as the association between the severe and very severe forms (group B) and the presence of sympathetic overactivity. These analyses were carried out by the SISA statistics program ("Simple Interactive Statistical Analysis"), estimating the relative risk, 95\%-confidence interval and the Fisher Test - the latter being statistically significant when the p-value was less than 0.05 ( $\mathrm{p}<0.05)$ (http://home.clara.net/sisa/). (Cited $21 \mathrm{Aug}$ 2001).

The intensity of dysautonomia in patients with and without sympathetic overactivity, detected by the Holter, and its clinical manifestations were also analyzed in relation to the clinical forms of tetanus. This was carried out through the difference between the means of the standard deviation of the normal R-to-R intervals in the groups studied. The means were calculated by the "Descriptive Statistics" program (http://www.physics.csbsju.edu/stats/descriptive2.html) (cited 22 Aug 2001), and the "Online Analysis of Data" was used for the analysis (http://glass.ed.asu.edu/stats/analysis/). (Cited 21 Aug 2001).

\section{RESULTS}

Thirty-eight patients admitted to the UCI took part in the study, of whom $89.4 \%$ were males. Mean age was $37.8 \pm 15$ years. Twenty-one $(55.3 \%)$ patients had very severe tetanus, $8(21 \%)$ severe, $7(18.4 \%)$ moderate and $2(5.3 \%)$ mild tetanus.

Table 1 shows the electrocardiographic alterations detected by the Holter, distributed by clinical form of tetanus.

Some patients were found to have more than one type of arrhythmia. Most had simple arrhythmias: 55.2\% (21/38) had isolated supraventricular extrasystoles and $39.4 \%(15 / 38)$ had isolated ventricular ones. Others also occurred but in a smaller number of patients: supraventricular extrasystoles in $21 \%$ (6/38), tachycardia in $5.2 \%(2 / 38)$, ventricular extrasystoles in $10.5 \%(4 / 38)$ and bigeminism in $5.2 \%(2 / 38)$. Conduction disturbances were also uncommon, being registered in $5.2 \%(2 / 38)$ of patients. 
HENRIQUES FILHO, G.T.; LACERDA, H.R.; ALBUQUERQUE, A. \& XIMENES, R.A.A. - Sympathetic overactivity and arrhythmias in tetanus: electrocardiographic analysis. Rev. Inst. Med. trop. S. Paulo, 49(1): 17-22, 2007.

Table 1

Distribution of tetanus cases according to the clinical form of the disease and the alterations detected by the 24-h Holter

\begin{tabular}{|c|c|c|c|c|c|}
\hline Clinical forms of tetanus & No. of cases & $\begin{array}{l}\text { Supraventricular } \\
\text { arrhythmias } \\
\mathrm{n}(\%)\end{array}$ & $\begin{array}{l}\text { Ventricular } \\
\text { arrhythmias } \\
\text { n }(\%)\end{array}$ & $\begin{array}{c}\text { Conduction } \\
\text { abnormalities } \\
\text { n }(\%)\end{array}$ & $\begin{array}{c}\text { Sympathetic } \\
\text { overactivity } \\
\mathrm{n}(\%)\end{array}$ \\
\hline Mild & 2 & $2(100.0)$ & $1(50.0)$ & $1(50.0)$ & $1(50.0)$ \\
\hline Moderate & 7 & $3(42.8)$ & $2(28.5)$ & - & $2(28.5)$ \\
\hline Severe & 8 & $6(75.0)$ & 7 (87.5) & - & $6(75.0)$ \\
\hline Very severe & 21 & $13(62.0)$ & $11(52.4)$ & $1(4.7)$ & $19(90.4)$ \\
\hline Total & 38 & $24(63.1)$ & $21(55.2)$ & $2(5.2)$ & $28(73.7)$ \\
\hline
\end{tabular}

Table 2

Frequency of arrhythmia detected by 24 hours Holter, in general and specific, such as: conduction abnormalities (CD), supraventricular (SVA) and ventricular (VA) arrhythmias, in 38 cases of accidental tetanus, admitted to the ICU-IPDS of the OCUH-PSU, distributed according to severity of clinical form of the disease, RecifePE, October 1998 to November 2000

\begin{tabular}{lccccc}
\hline Clinical forms & With arrhythmias in general ${ }^{\alpha}$ & With CD & With SVA & With VA $^{*}$ & 18 \\
Group B* & 25 & 01 & 19 & 03 & 29 \\
Group A** & 07 & 01 & 05 & 21 & 09 \\
Total cases & 32 & 02 & 24 & 38 \\
\hline
\end{tabular}

* Group B: composed of patients with severe and very severe tetanus; $* *$ Group A: composed of patients with mild and moderate tetanus. ${ }^{\alpha} \mathrm{RR}=1.11 / \mathrm{CI}(95 \%)=0.759$ - 1.618 / Fisher test: $\mathrm{p}=0.309(\mathrm{p}>0.05) ;{ }^{\beta} \mathrm{RR}=0.31 / \mathrm{CI}(95 \%)=0.021-4.477$ / Fisher test: $\mathrm{p}=0.371(\mathrm{p}>0.05) ;{ }^{\gamma} \mathrm{RR}=1.18 / \mathrm{CI}(95 \%)=0.621-2.239 /$ Fisher test: $\mathrm{p}=0.261(\mathrm{p}>0.05) ;{ }^{*} \mathrm{RR}=1.86 / \mathrm{CI}(95 \%)=0.708-4.896 /$ Fisher test: $\mathrm{p}=0.1(\mathrm{p}>0.05)$.

Table 3

Frequency of arrhythmia in general and specific, such as conduction abnormalities (CD), supraventricular (SVA) and ventricular (VA) arrhythmias, in 38 cases of accidental tetanus, admitted to the ICU-IPDS of the OCUH-PSU, distributed according to sympathetic overactivity (SO) detected by the 24 hours Holter. Recife-PE, October 1998 to November 2000

\begin{tabular}{lccccc}
\hline Results by Holter & With arrhythmias in general & With CD & With SVA & With VA $^{\beta}$ & 14 \\
With SO & 22 & 01 & 16 & 07 & 28 \\
Without SO & 10 & 01 & 08 & 21 & 10 \\
Total cases & 32 & 02 & 24 & 38 \\
\hline
\end{tabular}

${ }^{\alpha} \mathrm{RR}=0.79 / \mathrm{CI}(95 \%)=0.647-0.953 /$ Fisher test: $\mathrm{p}=0.13(\mathrm{p}>0.05) ;{ }^{\beta} \mathrm{RR}=0.36 / \mathrm{CI}(95 \%)=0.024-5.189 /$ Fisher test: $\mathrm{p}=0.398(\mathrm{p}>0.05) ;{ }^{\gamma} \mathrm{RR}=0.71 / \mathrm{CI}(95 \%)$ $=0.457-1.115 /$ Fisher test: $\mathrm{p}=0.141(\mathrm{p}>0.05) ;{ }^{\#} \mathrm{RR}=0.71 / \mathrm{CI}(95 \%)=0.412-1.237 /$ Fisher test: $\mathrm{p}=0.167(\mathrm{p}>0.05)$.

Tables 2 and 3 show the abnormalities of cardiac rhythm in general and specific rhythm disturbances detected by the Holter, according to the severity of the clinical form of tetanus (Table 2) and the presence of sympathetic overactivity on Holter (Table 3 ). The differences were not statistically significant.

Patients with severe or very severe clinical tetanus (Group B) were twice as likely to have sympathetic overactivity than patients with mild or moderate tetanus (Table 4). However, when comparing just the two categories in group B, even if the sample size is not large enough for the analysis of subgroups, the absence of a significant statistical difference and the confidence interval, which is not wide, suggest that severe tetanus cases have the same chance of developing SO as the very severe. Table 4 also shows the severity of this dysautonomia in relation to the different degrees of severity of tetanus (the SDNN value is inversely proportional to the intensity of sympathetic overactivity). The more severe patients (Group B) had a more intense adrenergic tonus (measured by SDNN values) than patients with a milder form of tetanus (Group A), the latter presenting a SDNN mean compatible with a normal sympathetic modulation (higher than 100 milliseconds). The difference was statistically significant.

The intensity of sympathetic overactivity detected by the Holter was not different between the different groups classified by severity of clinical forms of the tetanus (Table 5). Differences in the SDNN means were not found when comparing patients with sympathetic overactivity detected by Holter and clinical signs with those with no clinical signs (Table 5). 
Table 4

Frequency of sympathetic overactivity (SO) detected by the Holter and mean of standard deviation of HRV from the normal R-to-R intervals (SDNN) in 38 cases of tetanus, distributed according to severity of the clinical form of the disease

\begin{tabular}{lccc}
\hline Clinical forms & With SO & $\begin{array}{c}\text { Total } \\
\text { of cases }\end{array}$ & $\begin{array}{c}\text { SDNN } \\
\text { means }^{\beta}\end{array}$ \\
\hline Group B* & 25 & 29 & $64.1 \pm 27.3$ \\
$\quad$ Very severe tetanus & 19 & 21 & $62.9 \pm 29.0$ \\
$\quad$ Severe tetanus & 06 & 08 & $67.2 \pm 24.0$ \\
Group A** & 03 & 09 & $125.0 \pm 69.3$ \\
Total cases & 28 & 38 &
\end{tabular}

* Group B: patients with severe and very severe tetanus; ** Group A: patients with mild and moderate tetanus. Group B versus Group A: ${ }^{\alpha} \mathrm{RR}=2.59 / \mathrm{CI}(95 \%)$ $=1.015-6.589 /$ Fisher test: $\mathrm{p}=0.0042(\mathrm{p}<0.05) ;{ }^{\beta} \mathrm{CI}(95 \%)=30.55-91.25(\mathrm{p}$ $<0.05)$; Very severe tetanus versus severe tetanus: ${ }^{\alpha} \mathrm{RR}=1.21 / \mathrm{CI}(95 \%)=$ $0.789-1.842 /$ Fisher test: $\mathrm{p}=0.247(\mathrm{p}>0.05) ;{ }^{\beta} \mathrm{CI}(95 \%)=-27.99-19.39(\mathrm{p}>$ $0.05)$

Table 5

Mean of standard deviation of HRV from the normal R-to-R intervals (SDNN) recorded by the Holter in cases of tetanus with sympathetic overactivity (SO) detected by the Holter, distributed according to the clinical forms of the disease $^{\alpha}$, to the severity of tetanus ${ }^{\beta}$, and to the presence of clinical manifestations of dysautonomia ${ }^{\#}$

\begin{tabular}{lll}
\hline Cases with SO by Holter & $\begin{array}{c}\text { Number } \\
\text { of cases }\end{array}$ & $\begin{array}{c}\text { SDNN } \\
\text { means }\end{array}$ \\
\hline Clinical forms of tetanus & & \\
\hline Group B* & 25 & $57.3 \pm 18.1^{\alpha}$ \\
Very severe tetanus & 19 & $56.5 \pm 20.4^{\beta}$ \\
$\quad$ Severe tetanus & 06 & $59.7 \pm 8.04^{\beta}$ \\
Group A** & 03 & $66.0 \pm 13.1^{\alpha}$ \\
\hline
\end{tabular}

Clinical manifestations of dysautonomia

\begin{tabular}{lll}
\hline Yes & 14 & $58.9 \pm 18.9^{\#}$ \\
No & 14 & $57.5 \pm 16.9^{\#}$
\end{tabular}

* Group B: patients with severe and very severe tetanus; ** Group A: patients with mild and moderate tetanus. ${ }^{\alpha} \mathrm{CI}(95 \%)=-13.62-31.02(\mathrm{p}>0.05) ;{ }^{\beta} \mathrm{CI}$ $(95 \%)=-21.06-14.66(\mathrm{p}>0.05) ;{ }^{*} \mathrm{CI}(95 \%)=-12.53-15.33(\mathrm{p}>0.05)$.

\section{DISCUSSION}

The majority of the patients had the more severe forms of tetanus. The most frequent arrhythmias were isolated supraventricular and ventricular extrasystoles. Sympathetic overactivity was two and a half times more frequent in the more severe cases, but it was also detected in the milder forms of the disease. Half the patients had their sympathetic overactivity detected only by the Holter. There was no association of the arrhythmias with the clinical form of tetanus or with the presence of sympathetic overactivity.

The study design adopted, a case series with internal controls, may limit the inference of our findings. However this design may be very useful in the early stages of the development of knowledge about a particular topic and is justified, in this case, by the rarity or absence of studies on arrhythmias and sympathetic nervous system hyperactivity in the tetanus literature. It should be emphasized that it was not intended, in this stage, to establish a cause and effect relationship, but to detect an association between these electrocardiographic alterations and the severity of tetanus. It should be further explored in more powerful controlled studies.

The function of the autonomous nervous system can be evaluated by heart rate variability analysis (HRV) and can be determined by analysis of time or frequency ${ }^{11,12,22,24}$. This study used the HRV in relation to time, as there is a strong correlation between the variables determined by both methods ${ }^{24}$.

The variable used in this study was the mean of the standard deviation of the HRV from normal R-to-R intervals (SDNN), as there is a consensus that the combination of other markers of a 24-h analysis (Holter) is not necessary ${ }^{24}$.

The study showed that patients with severe clinical conditions have nearly two and a half times as much sympathetic overactivity than those with less severe conditions, which is to be expected. However, some with a moderate $(28.5 \%)$ or even a mild $(50 \%)$ form of the disease present an increase in sympathetic tonus. In these conditions tetanospasmin is probably less implicated in the etiology, while pain, starvation, anxiety, medications (specially curares) and infection may play a major role.

The data also showed that patients with severe tetanus had the same risk of having sympathetic overactivity than the very severe group. This result could be questioned, as there could be a problem of power for the subgroup analysis. However, a relative risk close to one and a narrow confidence interval does not suggest that a larger sample would change this conclusion. This apparent similarity is clinically relevant as the patients with severe tetanus have no indication for treatment of sympathetic overactivity but, as shown by this study, may have this condition with its potentially damaging effects on the cardiovascular system.

The study showed that the intensity of sympathetic overactivity is different between Groups A and B. However when we compared the SDNN means of just those patients who had sympathetic overactivity detected by the Holter, no statistically significant difference was found either between Groups A and B or between the two categories in Group B. Interestingly, there was no difference when we compared the SDNN means of patients who presented clinical sympathetic overactivity with those of patients in whom the condition was detected only by the Holter. In other words, all patients with clinical evidence of sympathetic overactivity had it also detected by the Holter; on the other hand, there were also patients for whom there was no clinical manifestation of dysautonomia but the holter detected sympathetic overactivity and it occurred even in those with mild and moderate forms of tetanus. These results suggest that the intensity of increase in the tonus of the sympathetic nervous system was similar in all groups of patients with this condition, irrespective of the clinical form or the presence of clinical manifestations. If these results are confirmed by other studies with a larger sample it could be suggested that the intensity of the dysautonomia is not the main determinant of the clinical manifestation of adrenergic hyperactivity and that other factors, besides the tetanus 
HENRIQUES FILHO, G.T.; LACERDA, H.R.; ALBUQUERQUE, A. \& XIMENES, R.A.A. - Sympathetic overactivity and arrhythmias in tetanus: electrocardiographic analysis. Rev. Inst. Med. trop. S. Paulo, 49(1): 17-22, 2007.

toxin, might play a role in the etiology of the sympathetic overactivity.

Arrhythmias are observed in tetanus patients, especially in the more severe forms, hypercatecholaminemia being the highest risk factor ${ }^{1,3,7,8,10,15,27}$. This study detected a low frequency of arrhythmias of clinical relevance and, unlike what was expected, there was no difference when we compared the presence of arrhythmia in general either between Groups A and B or between patients with and without sympathetic overactivity detected by 24 hours electrocardiographic (Holter) monitoring. Perhaps this occurred not only due to the sample size but also to a static evaluation of just one day in a long hospital sojourn. Thus a study with a larger sample size, or conducted with a longer period of follow-up or with analysis of a continuous monitoring of these patients, could determine the validity of this finding.

This study shows the importance of monitoring the cardiovascular system in tetanus, especially sympathetic overactivity. Considering the possibility of detecting early signs of sympathetic overactivity by the Holter, early treatment of this syndrome using morphine, magnesium sulfate, labetalol or fentany $1^{4,6,16}$ could result in a better clinical progression, lessening the effects not only of hypercatecholaminemia before they become clinically manifest, but also the severe complications resulting from sudden variations in blood pressure and heart rate.

\section{CONCLUSIONS}

Electrocadiographic monitoring of patients with tetanus by the $24 \mathrm{~h}-$ Holter showed that the mean of the standard deviation from the normal $\mathrm{R}$-to-R intervals may be useful in detecting autonomic dysfunction. Patients with the most severe forms had an almost two and a half times greater risk of developing sympathetic overactivity than those with the milder forms; however, a large number of patients not expected to have sympathetic overactivity, namely, the mild, moderate and severe cases, did, in fact, exhibit this alteration. Moreover, over half the patients had arrhythmias, usually the simple forms. This findings should be further explored in more powerful controlled studies.

\section{RESUMO}

\section{Hiperatividade simpática e arritmias no tétano: análise eletrocardiográfica}

Com os avanços no controle da insuficiência respiratória no tétano, o sistema cardiovascular tem participado de forma crescente na morbidade e mortalidade da doença, mas o conhecimento dessas complicações é escasso. No intuito de detectar arritmias e hiperatividade simpática, o holter de 24 h foi utilizado em 38 pacientes com tétano admitidos numa UTI de doenças infecciosas. O índice SDNN (desvio standard dos intervalos normais R-a-R), foi útil na detecção do tônus adrenérgico, e variou de 64,1 \pm 27 nas formas mais severas de tétano a $125 \pm 69$ nas formas mais leves. Hiperatividade simpática ocorreu em $86,2 \%$ das formas mais severas da doença, mas também foi identificada em $33 \%$ das formas leves. Cerca da metade dos pacientes tiveram sua hiperatividade simpática detectada apenas pelo Holter. As arritmias mais freqüentes foram extrassístoles isoladas, do tipo supraventriculares $(55,2 \%)$ ou ventriculares $(39,4 \%)$. Não houve associação das arritmias com a forma clínica do tétano ou com a presença de hiperatividade simpática. O presente estudo demonstrou que importantes alterações cardiovasculares, particularmente a hiperatividade simpática, ocorrem em todas as formas de tétano, mesmo as mais leves. Estas alterações não estão sendo detectadas pelos métodos tradicionais de monitorização em UTI, podendo resultar em falhas na abordagem terapêutica.

\section{REFERENCES}

1. ABRUTYN, E. - Tetanus. In: ISSELBACHER, K.J.; BRAUNWALD, E.; WILSON, J.D. et al. Harrison's principles of internal medicine. 15 ed. New York, McGraw-Hill, 2001. p. $918-920$.

2. BARDENHEIER, B.; PREVOTS, D.R.; KHETSURIANI, N. \& WHARTON, M. -Tetanus surveillance - United States, 1995-1997. M.M.W.R., 47: 1-13, 1998.

3. BARTLETT, J.G. - Tetanus. In: GOLDMAN, L. \& AUSIELLO, D., ed. Cecil textbook of Medicine. 22. ed. New York, W. B. Saunders, 2004. p. 1841-1842.

4. BLECK, T.P. - Clostridium tetani (Tetanus). In: MANDELL, G.L.; BENNETT J.E. \& DOLIN, R., ed. Principles and practice of infectious diseases. 6. ed. New York, Churchill Livingstone, 2005. p. 2817-2821.

5. CORBETT, J.L.; KERR, J.H.; PRYS-ROBERTS, C.; SMITH, A.C.C. \& SPALDING, J.M.K. - Cardiovascular disturbances in severe tetanus due to overactivity of the sympathetic nervous system. Anaesthesia, 24: 198-212, 1969.

6. DOMINIGHETTI, G.M.; SAVARY, G. \& STRICKER, H. - Hyperadrenergic syndrome in severe tetanus: extreme rise in catecholamines responsive to labetalol. Brit. med. J., 288: 1483-1484, 1984

7. HOLLOW, V.M. \& CLARKE, G.M. - Autonomic manifestations of tetanus. Anaesth. intens. Care, 3: 142-147, 1975.

8. HÖRTNAGL, H.; BRÜCKE, T. \& HACKL, J.M. - The involvement of the sympathetic nervous system in tetanus. Klin. Wochenschr., 57: 383-389, 1979.

9. LEE, H.C.; KO, W.C. \& CHUANG, Y.C. - Tetanus in the elderly. J. Microbiol. Immunol. Infect., 33: 191-196, 2000.

10. LONGO, M.R. \& MARK, H. - Electrocardiographic abnormalities in generalized tetanus. J. Electrocardiol., 4: 271-274, 1971.

11. MALIK, M. \& CAMM, A.J. - Heart rate variability. New York, Futura, 1995. p. 1-23.

12. MANSIER, P.; CLAIRAMBAULT, J.; CHARLOTTE, N. et al. - Linear and non-linear analysis of heart rate variability: a minireview. Cardiovasc. Res., 31: 371-379, 1996.

13. MIRANDA-FILHO, D.B.; XIMENES, R.A.A.; BARONE, A.A. et al. - Randomised controlled trial of tetanus treatment with antitetanus immunoglobulin by the intrathecal or intramuscular route. Brit. med. J., 328: 615, 2004.

14. MIRANDA-FILHO D.B.; XIMENES R.A.A.; BERNARDINO, S.N. \& ESCARIÃO, A.G - Identification of risk factors for death from tetanus in Pernambuco, Brazil: a casecontrol study. Rev. Inst. Med. trop. S. Paulo, 42: 333-339, 2000.

15. MITRA, R.C.; GUPTA, R.D. \& SACK, R.B. - Electrocardiographic changes in tetanus: a serial study. J. Indian med. Ass., 89: 164-167, 1991.

16. MOUGHABGHAB, A.V.; PREVOST, G. \& SOCOLOVSKY, C. - Fentanyl therapy controls autonomic hyperactivity in tetanus. Brit. J. clin. Pract., 50: 477-478, 1996.

17. NISHANIAN, E. - Can epidural anesthesia change the mortality rate of tetanus? Crit. Care Med., 27: 1721-1725, 1999.

18. PATEL, J.C. \& MEHTA, B.C. - Tetanus: study of 8,697 cases. Indian J. med. Sci., 53 393-401, 1999. 
HENRIQUES FILHO, G.T.; LACERDA, H.R.; ALBUQUERQUE, A. \& XIMENES, R.A.A. - Sympathetic overactivity and arrhythmias in tetanus: electrocardiographic analysis. Rev. Inst. Med. trop. S. Paulo, 49(1): 17-22, 2007.

19. PEETERMANS, W.E. \& SCHEPENS, D. - Tetanus - still a topic of present interest: a report of 27 cases from a Belgian referral hospital. J. intern. Med., 239: 249-252, 1996

20. ROSE, A.G. - Catecholamine-induced myocardial damage associated with phaeochromocytomas and tetanus. S. Afr. med. J., 48: 1285-1289, 1974.

21. SANDERS, R.K. - The management of tetanus. Trop. Doctor, 26: 107-115, 1996.

22. SOCIEDADE BRASILEIRA DE CARDIOLOGIA - Meios diagnósticos não invasivos nas arritmias cardíacas: eletrocardiografia dinâmica pelo sistema Holter e avaliação da função autonômica cardíaca. Temas de atualização: arritmias cardíacas, 2: 1$18,1998$.

23. SUINAT, J.L.; RENDOING, J. \& CAULET, T. - Myocardiopathie et sécrétion de catécholamines au cours du tétanos. Nouv. Presse méd., 9: 3282, 1980.

24. TASK FORCE OF THE EUROPEAN SOCIETY OF CARDIOLOGY AND THE NORTH AMERICAN SOCIETY OF PACING AND ELECTROPHYSIOLOGY - Heart rate variability: standards of measurement, physiological interpretation and clinical use. Circulation, 93: 1043-1465, 1996.
25. TOMASZunAS-BlaszCZYK, J. - Tetanus in 1997. Przegl. Epidem., 53: 129-135, 1999.

26. TSUEDA, K.; JEAN-FRANÇOIS, J. \& RICHTER, R.W. - Cardiac standstill in tetanus: review of seven consecutive cases. Int. Surg., 58: 599-603, 1973.

27. TSUEDA, K.; OLIVER, P.B. \& RICHTER, R.W. - Cardiovascular manifestation of tetanus. Anesthesiology, 40: 588-592, 1974.

28. VALIATTI, J.L. - Tétano. In: RATTON, J.L.A. Medicina intensiva. 2. ed. Belo Horizonte, Atheneu, 1997. p. 317-325.

29. VAN LIESHOUT, J.J.; WIELING, W.; ROMIJIN, J. \& STAM, J. - Hyperadrenergic syndrome with hypertension, hypotension and myocardial necrosis in tetanus. Neth. J. Med., 33: 33-36, 1988.

30. VERONESI, R.; FOCACCIA, R.; TAVARES, W. \& MAZZA, C.C. - Tétano. In: VERONESI, R. \& FOCACCIA, R. Tratado de infectologia. Rio de Janeiro, Atheneu, 2005. p. 887-911.

Received: 28 March 2006

Accepted: 4 August 2006 